\title{
LOS DERECHOS HUMANOS DE LOS INMIGRANTES DE LA FRONTERA SUR DE MÉXICO
}

\section{HUMAN RIGHTS OF IMMIGRANTS FROM THE SOUTHERN BORDER OF MEXICO}

\author{
Rosa Cornelio Landero \\ Universidad Juárez Autónoma de Tabasco. México/Mexico \\ rosecorlan@hotmail.com
}

Recibido/Received: 10/02/2015

Aceptado/Accepted: 29/04/2015

\begin{abstract}
RESUMEN
Los derechos humanos de los inmigrantes en diversas fronteras del mundo es uno de los fenómenos sociales y políticos que ha preocupado a diversas Organizaciones Internacionales, que buscan siempre combatir el clima de impunidad y violaciones a los derechos que persiste en la situación de las personas que son inmigrantes y que llegan a un Estado, porque son perseguidos por escapar de sus hogares por conflictos armados, entre otras circunstancias, situación que México es considerado uno de los países que concentra más migrante que pasan por la Frontera Sur de México para llegar a los Estados Unidos (EE.UU.). El presente trabajo es con la finalidad de conocer cuáles son las Normas Internacionales y mexicanas que protegen a los inmigrantes en el tránsito por la Frontera Sur de México, analizar cuáles son los derechos con los que cuenta la persona considerada como inmigrante, cuando se violan los Derechos Humanos como persona.
\end{abstract}

\section{PALABRAS CLAVE}

Persona, derecho, violación, justicia.

\section{SUMARIO}

1. Introducción. 2. Derechos humanos de los inmigrantes. 3. Obligación del Estado Mexicano en dar la seguridad al inmigrante. 4. Violaciones a los derechos humanos que sufren los inmigrantes de la Frontera Sur de México. 5. Conclusión. Bibliografía.

\begin{abstract}
Human rights of migrants in various borders in the world is one of the social and political phenomena that has worried many international organizations, which always seeks to fight for the rights that persists in the situation of people the climate of impunity and violations that are immigrants arriving in a state, because they are persecuted by flee their homes by armed conflict, among other circumstances, a situation that Mexico is considered one of the countries that concentrates more migrants passing through the southern border of Mexico to reach the United States (USA). This work is in order to know what the international and Mexican standards protecting migrants in transit through the Southern Border of Mexico, analyze what rights are there in person Immigrant are considered when violate Human Rights as a person.
\end{abstract}

\section{KEYWORDS}

Person, law, rape, justice. 


\section{CONTENTS}

1. Introduction. 2. Human rights of migrants. 3. Obligation of the Mexican State to provide security to immigrant. 4. Human rights violations suffered by immigrants from the southern border of Mexico. 5. Conclusions. References.

\section{INTRODUCCIÓN}

El hombre en su camino encuentra barreras que cruzar, quizás en unas lo haga con libertad, pero en otras tendrá que enfrentar el peligro, que lo llevara a estar sometido o inmerso en diversos conflictos, el individuo que vive en una sociedad jurídicamente organizada, necesita una realización efectiva necesaria para desarrollarse dentro de la sociedad; Juan Jacobo Rousseau, en su libro el Contrato Social, escribe que "el hombre ha nacido libre, y sin embargo, vive en todas partes entre cadenas" (Rousseau, 2013). El Estado tiene una de las tareas más trascendentales, que es el de proteger los Derechos Humanos de todo individuo, está obligado a mantener las condiciones necesarias para que toda persona goce de sus derechos, acceso a la paz, justicia, libertad y el bienestar común.

La Convención Americana, protege los derechos humanos de los inmigrantes de acuerdo a lo que señala en los artículos 4, 5, 6 y 7 de dicha Convención, están protegidos los derechos a la vida, a la integridad personal, a la libertad, todas y los demás relativos a la seguridad ciudadana, México tiene leyes vigentes que protegen los derechos humanos de las personas, que emanan de nuestra Constitución Política vigente, en el artículo $1^{\circ}$ que señala que en los Estados Unidos Mexicanos todas las personas gozarán de los derechos humanos reconocidos en esta Constitución y en los Tratados Internacionales de los que el Estado Mexicano sea parte y garantizar su protección.

\section{DERECHOS HUMANOS DE LOS INMIGRANTES}

Los derechos humanos comprenden todas las necesidades primordiales propias del hombre, como ser humano que se proyecta como persona física, siendo que los derechos humanos abarcan a todo individuo por el hecho de ser tal. El individuo que vive en una sociedad jurídicamente organizada, necesita una realización efectiva y necesaria para desarrollarse dentro de la sociedad. El Estado tiene una de las tareas mas trascendentales, que es el de proteger los derechos humanos de todo individuo y está obligado a mantener las condiciones necesarias para que toda persona goce de sus derechos, acceso a la paz, justicia, libertad y el bienestar común.

La Declaración Universal de Derechos Humanos, en el artículo $1^{\circ}$, señala que: "todos los seres humanos nacen libres e iguales en dignidad y derechos y, dotados como están de razón y conciencia, deben comportarse fraternalmente los unos con los otros" (Unidas, 1948). Es decir, que cada individuo debe de respetarse primeramente como persona y reconocerse así mismo, por dignidad propia, pero también demostrar su respeto para con el prójimo a través de su conducta que demuestre en el círculo social donde se desenvuelve.

Los Derechos humanos son consustanciales a todos los seres humanos como lo prevé la Declaración Universal de Derechos Humanos en el artículo 2, "que toda persona tiene los derechos y libertades proclamados en esta Declaración, sin distinción alguna de raza, color, sexo, idioma, religión, opinión política o de cualquier otra índole, origen nacional o social, 
posición económica, nacimiento o cualquier otra condición" (Unidas, 1948). Además, no se hará distinción alguna fundada en la condición política, jurídica o internacional del país o territorio de cuya jurisdicción dependa una persona, tanto si se trata de un país independiente, como de un territorio bajo administración fiduciaria, no autónomo o sometido a cualquier otra limitación de soberanía. Estos derechos que se encuentran bien definidos, es claro que todo ser humano se encuentra protegido en cualquier espacio, lugar y modo en donde se ubique o radique, por el simple hecho de ser un humano los tratados internacionales le han concedido tal derecho, para el caso de que algún Estado haga caso omiso a este tratado está violentando el derecho de la persona.

El Derecho a la vida, a la libertad y a la seguridad de la persona, que señala el artículo $3^{\circ}$ de la Declaración Universal de Derechos Humanos, en nuestros tiempos es difícil creer que el Estado no quite la vida a los individuos en diversas formas, sin que las leyes tanto internacionales como nacionales puedan ser aplicada, al igual que la libertad, es frecuente escuchar por diferentes medios que se le priva de la libertad a diversas personas, sin tener en claro si es culpable del delito o no, desde ese tenor podemos partir de que las leyes no son aplicadas con equidad, si analizamos a fondo este artículo tal cual y se aplicara en realidad, no existiera tanta desigualdad y violaciones a los derechos del individuo, la libertad del ser humano no solo es un derecho básico, sino también es un valor fundamental, también la seguridad personal es un derecho que tiene el Estado que otorgar, el Estado está obligado a proporcionar y garantizar a todo la población, siendo un derecho de carácter personal, lo tiene tanto el individuo nacional como el extranjero.

El Pacto Internacional de Derechos Civiles y Políticos, constituye una amplia base jurídica para la protección de cada persona, como lo disponen los artículos 2 y 6 , regula que cada uno de los Estados partes del pacto están comprometidos a respetar y garantizar a todos los individuos que se encuentran en el territorio y estén sujetos a la jurisdicción los derechos que reconoce dicho pacto, sin hacer distinción alguna de raza, color, sexo, idioma, religión, opinión política o de otra índole de origen nacional o social, posición económica nacimiento, o cualquier condición social. También se compromete adoptar con arreglo a sus procedimientos constitucionales y a las disposiciones del mencionado Pacto. De igual manera, señala que el derecho a la vida es inherente a la persona humana y está protegido por la ley, prohíbe también que se prive de las persona de manera arbitraria.

El artículo 2 del Pacto Internacional de Derechos Económicos, Sociales y Culturales (PIDESC, 1981), señala que: "los Estado que forman parte del presente Pacto están comprometidos a garantizar el ejercicio de los derechos que en él se enuncian sin discriminación alguna por motivos de raza, color, sexo, idioma, religión, opinión política o de otra índole, origen nacional o social, posición económica nacimiento o cualquier otra condición social". Los países en vías de desarrollo, teniendo en cuenta los derechos humanos y su economía nacional, podrán determinar en qué medida garantizarán los derechos económicos reconocidos en el presente Pacto a personas que no sean nacionales suyos, reconociendo que los derechos pactados son parte de la dignidad inherente a los individuos, es también una obligación del Estado de hacer que los derechos humanos sean respetados de manera universal.

La Convención Internacional sobre la Protección de los Derechos de Todos los Trabajadores Migratorios y de sus Familias, adoptada en Nueva York, EUA, de 18 de diciembre de 1990, ratificada por México el 8 de marzo de 1999, en el artículo 7, tiene aplicación para todos los trabajadores migratorios y a sus familiares sin distinción alguna por motivos de sexo, raza, color, idioma, religión o convicción, opinión política o de otra índole, 
origen nacional, étnico o social, nacionalidad, edad, situación económica, patrimonio, estado civil, nacimiento o cualquier otra condición, pero también será aplicable durante el proceso de migración de los trabajadores migratorios y sus familiares, que comprende la preparación para la migración, la partida, el tránsito y todo el período de estancia y de ejercicio de una actividad remunerada en el Estado de empleo, así como el regreso al Estado de origen o al Estado de residencia habitual.

La observancia y la defensa de los derechos humanos es una de las funciones principales de la Convención Americana sobre Derechos Humanos de 1969, con las Declaraciones Interpretativas al párrafo $1^{\circ}$ del artículo 4 y al artículo 12 y la reserva al artículo 23 , párrafo 2, que formulara el Ejecutivo de la Unión al proceder a su adhesión, en el artículo 41, establece cual es la función principal de la Comisión dentro de las cuales se encuentran la de estimular la conciencia de los derechos humanos en los pueblos de América; formular recomendaciones, cuando lo estime conveniente, a los gobiernos de los Estados miembros para que adopten medidas progresivas en favor de los derechos humanos dentro del marco de sus leyes internas y sus preceptos constitucionales, al igual que disposiciones apropiadas para fomentar el debido respeto a esos derechos; preparar los estudios o informes que considere convenientes para el desempeño de sus funciones; solicitar de los gobiernos de los Estados miembros que le proporcionen informes sobre las medidas que adopten en materia de derechos humanos; atender las consultas que, por medio de la Secretaría General de la Organización de los Estados Americanos, le formulen los Estados miembros en cuestiones relacionadas con los derechos humanos y, dentro de sus posibilidades, les prestará el asesoramiento que estos le soliciten, actuar respecto de las peticiones y otras comunicaciones en ejercicio de su autoridad de conformidad con lo dispuesto en los artículos 44 al 51 de esta Convención. Por consiguiente, el respeto y vigencia de los derechos humanos en los países de origen es la mejor manera de prevenir los movimientos forzados de personas que de manera constante se vive, más frecuente es lo que sucede en la Frontera Sur de México, con los inmigrantes.

\section{OBLIGACIÓN DEL ESTADO MEXICANO EN DAR LA SEGURIDAD AL INMIGRANTE}

La seguridad de los inmigrantes es un derecho que protege la Convención Americana, de acuerdo a lo que señalan los artículos 4, 5, 6 y 7 de dicha Convención, están protegidos los derechos a la vida, a la integridad personal, a la libertad, todas y los demás relativos a la seguridad ciudadana, pero no podemos dejar de invocar el artículo $1^{\circ}$ de la misma convención que establece que los Estados partes en esta Convención se comprometen a respetar los derechos y libertades reconocidos en ella y a garantizar su libre y pleno ejercicio a toda persona que esté sujeta a su jurisdicción, sin discriminación alguna por motivos de raza, color, sexo, idioma, religión, opiniones políticas o de cualquier otra índole, origen nacional o social, posición económica, nacimiento o cualquier otra condición social, es decir el Estado tiene la capacidad para garantizar la seguridad como persona a todos los que se encuentren en su jurisdicción.

En lo que respecta a la violencia que se ha generado, en la frontera sur de México, cada día es más peligroso, donde la vigencia de los Derechos Humanos está en juego, la Comisión como la Corte Interamericana han condenado la impunidad de hechos que vulneran derechos fundamentales ya que ésta propicia la repetición crónica de las violaciones de derechos humanos y la total indefensión de las víctimas y de sus familiares. Aunque México ha 
adoptado y es parte de la Convención Americana no ha cumplido con lo pactado en la misma en brindarle la seguridad necesaria y suficiente a las personas que transitan por su Frontera Sur, además que en la Constitución Federal de México en el artículo $1^{\circ}$, también se compromete a hacer valer y respetar los Derechos Humanos, es claro que se ha violentado tanto el Derecho Internacional como las Normas Jurídicas que rigen a México.

México comparte la frontera sur con los países de Guatemala y Belice aproximadamente 1200 kilómetros, de los cuales $970 \mathrm{~km}$ limitan con Guatemala. En esta zona se encuentran ubicadas 29 de las 52 estaciones migratorias que existen en México, lo que ha provocado que México tenga compromisos internacionales bien definidos en lo que respecta a Derechos Humanos, ha ratificado importantes Tratados Internacionales como son: el Pacto Internacional de Derechos Civiles y Políticos (entrado en vigor para México: 23 junio 1981), la Convención Americana sobre Derechos Humanos (24 marzo 1981), la Convención contra la Tortura y otros Tratos o Penas Crueles, Inhumanos o Degradantes (26 junio 1987), la Convención Interamericana para Prevenir y Sancionar la Tortura (22 julio 1987), la Convención sobre los Derechos del Niño (21 octubre 1990), la Convención Internacional sobre la Protección de los Derechos de todos los Trabajadores Migratorios y de sus Familiares ( $1^{\circ}$ julio de2003), entre otros más.

La Constitución Política de los Estados Unidos Mexicanos en el artículo 2, inciso B, fracción VIII, obliga a las autoridades federales, estatales, y municipales a llevar adelante políticas sociales en protección de los migrantes; también en el artículo 33 constitucional reconoce a los extranjeros las mismas garantías y derechos que los dispensados a los nacionales, por lo que el Estado deberá prevenir, investigar, sancionar y reparar las violaciones a los derechos humanos, en los términos que establezca la ley. En el artículo 11 de la Ley fundamental, señala que toda persona tiene derecho para entrar en la República, salir de ella, viajar por su territorio y mudar de residencia, sin necesidad de carta de seguridad, pasaporte, salvoconducto $\mathrm{u}$ otros requisitos semejantes. El ejercicio de este derecho estará subordinado a las facultades de la autoridad judicial, en los casos de responsabilidad criminal o civil, y a las de la autoridad administrativa, por lo que toca a las limitaciones que impongan las leyes sobre emigración, inmigración y salubridad general de la República, o sobre extranjeros perniciosos residentes en el país. En caso de persecución, por motivos de orden político, toda persona tiene derecho de solicitar asilo; por causas de carácter humanitario se recibirá refugio.

La ley de Migración en el artículo $2^{\circ}$ establece que el Estado Mexicano busca las estrategias necesarias para la creación y aplicación de programas y acciones con el objetivo de atener los asuntos migratorios de México de manera integral, como país de origen, tránsito, destino y retorno de migrante, esta Ley señala que el Estado mexicano tiene principios como son: el respeto irrestricto de los derechos humanos de los migrantes, ya sean nacionales como extranjeros, sea cual fuere su origen, nacionalidad, género, etnia, edad y situación migratoria, con especial atención a grupos vulnerables como menores de edad, mujeres, indígenas, adolescentes y personas de la tercera edad, así como a víctimas del delito; congruencia en garantizar la vigencia de los derechos que reclama para sus connacionales en el exterior en la admisión, ingreso, permanencia, tránsito, deportación y retorno asistido de extranjeros en su territorio, es responsable con los gobiernos de diversos países con relación a temas migratorios; facilita la movilidad internacional de personas, salvaguardando el orden y la seguridad.

El principio mencionado reconoce el aporte de los migrantes a las sociedades de origen y destino; busca la equidad entre nacionales y extranjeros, como indica la Constitución Política 
de los Estados Unidos Mexicanos, especialmente en lo que respecta a la plena observancia de las garantías individuales, tanto para nacionales como para extranjeros; reconoce los derechos adquiridos de los inmigrantes, en tanto que los extranjeros con arraigo o vínculos familiares, laborales o de negocios en México han generado una serie de derechos y compromisos a partir de su convivencia cotidiana en el país, aun cuando puedan haber incurrido en una situación migratoria irregular por aspectos administrativos y siempre que el extranjero haya cumplido con las leyes aplicables.

El Estado mexicano garantizará el ejercicio de los derechos y libertades de los extranjeros reconocidos en la Constitución, en los tratados y convenios internacionales de los cuales sea parte el Estado mexicano y en las disposiciones jurídicas aplicables, con independencia de su situación migratoria, que se encuentran reglamentamos en la Ley de Migración en los artículos 6, 7 y 8, de igual forma expresa la libertad de toda persona para ingresar, permanecer, transitar y salir del territorio nacional tendrá las limitaciones establecidas en la Constitución, los tratados y convenios internacionales de los cuales sea parte el Estado mexicano, esta Ley y demás disposiciones jurídicas aplicables, los migrantes podrán acceder a los servicios educativos provistos por los sectores público y privado, independientemente de su situación migratoria y conforme a las disposiciones legales y reglamentarias aplicables, los migrantes tendrán derecho a recibir cualquier tipo de atención médica, provista por los sectores público y privado, independientemente de su situación migratoria.

La normatividad protectora de los Derechos Humanos en México, sigue los principios de universalidad, interdependencia, indivisibilidad y progresividad, como lo señala la Ley de la Comisión Nacional de los Derechos Humanos, en el artículo 4, refiere la defensa y promoción, también regula las facultades que tiene la Comisión, quien deberá de seguir los procedimientos más sencillo posible pero sin dejar la formalidad requerida por cada expedientes, además deberán de seguir los principios de inmediatez, concentración y rapidez, darle de manera pronta la importancia que tiene cada uno de los asuntos, buscar tener contacto con los quejosos, denunciantes y la autoridad respectivamente, para lograr la atención de manera eficiente y humana posible, evitar siempre que la comunicación por escrito haga del proceso más dilatado.

Los migrantes abandonan un lugar por otro buscando condiciones de vida digna, una mejor educación, escapando de persecuciones o simplemente para reunirse con familiares o amigos, desconociendo lo que señala el Convenio Internacional sobre Derechos Económicos, Sociales y Culturales, con relación a los derechos sociales básico que tiene los inmigrantes como son: nivel de vida adecuado para sí y su familia, incluso alimentación, vestido y vivienda adecuados, y a una mejora continua de las condiciones de existencia, además reconociendo el derecho fundamental de toda persona a estar protegida contra el hambre, adoptarán, individualmente y mediante la cooperación internacional, las medidas, incluidos programas concretos, que se necesiten para mejorar métodos de producción, divulgar los principios sobre nutrición, como utilizar de manera eficiente las riquezas naturales, la distribución equitativa de los alimentos mundiales.

El tránsito de los inmigrantes por el territorio mexicano, en especial en la Frontera Sur de México, es complejo, debido que todos están expuesto a extorsión, robos, secuestros, trata de persona, explotación sexual y en general a violaciones a los derechos humanos, esto ha sido preocupante para Instituciones gubernamentales y no gubernamentales, que han procurado mejorar la protección de los migrantes, pero en realidad lo han hecho más las sociedades civiles que se han formado por la necesidad que cada vez es más grande.

Existe medidas legislativas del Estado mexicano en que regulan la protección a migrantes como son la Ley de migración, la Ley sobre Refugiados y Protección Complementaria, la ley 
para Prevenir y sancionar la trata de personas, entre otras, sin embargo, es necesario trabajar en el fortalecimiento para prestar la protección en seguridad humana de los inmigrantes. La Comisión Interamericana de Derechos Humanos (CIDH), en el 2014 presentó en la Ciudad de México su informe "Derechos humanos de los migrantes, la CIDH expresó su preocupación por la situación de extrema vulnerabilidad de las personas migrantes en México, a la que llamó como una tragedia humanitaria, hace un reconocimiento especial al trabajo de la sociedad civil y a las y los defensores de derechos humanos de migrantes en México.

El gobierno mexicano ha diseñado una Estrategia de Atención Integral a la Frontera Sur, que consiste en el Programa Frontera Sur y la Coordinación para la Atención Integral de la Frontera Sur, que se enfoca en el control migratorio, que debe estar coordinado por las autoridades federales, estatales y municipales, pero no ha trabajado en la corrupción que se vive entre las corporaciones judiciales que se encuentran en la frontera sur, este programa está operando por dos años a partir del 13 de enero de 2013, dijo, beneficiará a 300 mil migrantes en tránsito por la frontera sur de México, en donde las principales acciones será capacitar a 800 funcionarios gubernamentales y 14 albergues de migrantes en los Estados de Chiapas, Oaxaca y Tabasco, y tendrá un presupuesto de 3 millones 100 mil dólares, razón por la cual solo operará en esas entidades. Este proyecto mexicano está complementado por el Alto Comisionado de la Naciones Unidas para los Refugiados (ACNUR) el Fondo de Población de las Naciones Unidas (UNFPA), la Oficina de las Naciones Unidas para las Drogas y el Delito (ONUDD), la Organización Internacional de las Migraciones (OIM), el Programa de Naciones Unidas para el Desarrollo (PNUD), la Entidad de las Naciones para la Igualdad y género y el Empoderamiento de la Mujer, (ONU Mujeres), el Fondo de Naciones Unidas para la Infancia (UNICEF) y la Organización Internacional del Trabajo (OIT), entre las 39 recomendaciones que realiza la CIDH destaca la urgencia de garantizar los derechos de migrantes como víctimas de delitos y violaciones a derechos humanos.

La creación del Programa Especial de Migración (PEM) 2014-2018 no ha sido suficiente para la defensa de los derechos humanos de los inmigrantes que transitan por la Frontera Sur de México, por lo que se han formado diversas organizaciones y redes para apoyar en la defensa de los derechos de inmigrantes que sufren abusos, la política migratoria de México y su base para la protección de los derechos humanos debe de estar regulada por el Derecho Internacional. Es de resaltar que la creación del Programa Especial de Migración es uno de los elementos positivo del Estado mexicano que ha presentado en estos años, sin embargo, no es suficiente, existen más de 120 redes y organizaciones que se encuentran registradas en Colectivo Migraciones para las Américas (COMPA), organizaciones y redes que se han ido conformando en Estados Unidos, México y Centroamérica, por mencionar algunas se encuentran: Agencia Familiar Binacional, AC (AFABI); Albergue de Migrantes Hermanos en el Camino; Albergue del Desierto; Albergue Manos Extendidas a los Necesitados, AC; Asamblea Popular de Familias Migrantes (APOFAM); Asociación Mexicana de Uniones de Crédito del Sector Social (AMUCSS); Association of Mexicans in North Carolina (AMEXCAN); Asociación Mexicana pro Naciones Unidas, AC; Babel Sur, Centro de Investigación Política y Alternativas Sociales, AC; Be Foundation, Derecho a la Identidad, AC; Benemérita Universidad Autónoma de Puebla (BUAP), Caridad Sin Fronteras, AC; Catholic Relief Services; Casa Refugiados, AC; Centro Bonó; Centro Internacional para los Derechos Humanos de los Migrantes (CIDEHUM); Coordinación de Migración (BUAP); Boca de Polen Red de Comunicadores; Casa del Migrante Casa Nicolás; CEMAC, AC; Centro Comunitario de Atención al Migrante y Necesitado (CCAMYN); Centro de 
Alternativas para el Desarrollo Social, AC (CADES); Centro de Apoyo al Trabajador Migrante; Centro de Asistencia para Refugiados (CEALP); Facultad de Ciencias Políticas y Sociales UNAM; Federación Zacatecana, AC (FEDZAC), quienes han solicitado al gobierno mexicano, que se publiquen los documentos que contienen el Proyecto y directrices del Plan Frontera Sur, puesto que desde su entrada en operación tenemos registro de que se han incrementado las agresiones por parte del Instituto Nacional de Migración y Policía Federal en contra de las personas migrantes.

El seguimiento a la política migratoria el gobierno de México el 8 de julio de 2014, creó la Coordinación de Atención Integral de la Migración en la Frontera Sur, con la finalidad de atender el fenómeno migratorio en Campeche, Chiapas, Quintana Roo y Tabasco, el Secretario de Gobernación, nombró un titular a esa Coordinación, con el objetivo de ordenar los cruces internacionales, atender el fenómeno de la migración infantil e implementar acciones para el respeto a los derechos humanos y el tránsito seguro de los flujos migratorios, buscando también hacer de la frontera sur sea una zona de estabilidad social, fortaleciendo la seguridad en la región del país con los países centroamericanos.

\section{VIOLACIONES A DERECHOS HUMANOS QUE SUFREN LOS INMIGRANTES DE LA FRONTERA SUR DE MÉXICO}

Es constante en la Frontera Sur de México ver el tránsito de inmigrantes, hasta la fecha ha sido uno de los territorios que no se ha aplicado las leyes, ni respeta los Derechos Humanos, debido a que diariamente pasa gente de los países vecinos como Guatemala, Honduras y el Salvador, aunque no hay una estadística fiable que diga la cantidad de personas que cruza a diario por esa zona, algunos mueren, datos que quizás nunca se sabrá con certeza, por los que se puede conocer los que informa del Instituto Nacional de Migración, aunque no son fiables, pues no alcanzan a interceptar a todas las personas que de ahí transitan rumbo a los Estados Unidos (EU), todos pueden pasar de un lado a otro porque la balsa solo le cobra de 2 a 5 dólares para cruzar el río Suchiate que marca la frontera de México con Guatemala, nadie les pide documento alguno, ni las autoridades de Guatemala ni las Mexicanas.

Centenares de inmigrantes latinoamericanos emprenden uno de los viajes más peligrosos, cruzar México en tren, a bordo de ferrocarriles de carga conocidos como La Bestia o El tren de la Muerte, estos trenes son una trampa mortal para los inmigrantes quienes enfrentan el peligro de sufrir una amputación al caer del tren y ser arrollados o encontrar su muerte. Pero estos no son los únicos peligros que ocasiona "la bestia", hombres, mujeres y hasta niños que viajan en los vagones son constantemente violados, secuestrados por grupos delictivos que operan en la zona; en 2010, 72 inmigrantes centroamericanos fueron asesinados por el cartel de los Zetas en Tamaulipas, todos ellos buscaban cruzar a los Estados Unidos, el 25 de agosto de 2014, al menos 12 inmigrantes centroamericanos murieron cuando un tren de carga descarriló en Tabasco, el gobierno de Tabasco reportó que de acuerdo con información de la Secretaría de Seguridad Pública del Estado (SSPE) y de la 30 Zona Militar, 250 ciudadanos hondureños viajaban en el tren, viajar en este tren es jugarse la vida en un trayecto que dura de 20 a 25 días, en atravesar México para llegar a la frontera norte con los Estados Unidos, el costo es alrededor de $\$ 1,200$ dólares por migrante, porque no es gratis el traslado.

Los inmigrantes deberán de seguir jugándose la vida por tratar de atravesar México en su travesía hacia los Estados Unidos en busca del "sueño americano", una mejor vida para su familia, que muchas veces termina con cuerpos sin nombre en fosas comunes de México, organizaciones no gubernamentales, propusieron que haya un permiso temporal de tránsito 
que ayude a los centroamericanos a viajar protegidos por el país, sin embargo, la propuesta no fue aprobada por los legisladores. Son cientos de personas de Centroamérica, e incluso de América del Sur, intentan cruzar el territorio mexicano en el tren llamado "La Bestia", tren de carga que parte en Arriaga, Chiapas, y que llega a Nuevo Laredo, Tamaulipas, punto de cruce con los Estados Unidos. Además, se indica que en la región Sur-sureste se ubica la frontera con más afluencia migratoria en el mundo, pues según el Instituto de Migración ingresan cerca de 150 mil personas anualmente en su mayoría de Honduras, Guatemala y el Salvador, con la intención de llegar a cumplir el llamado Sueño Americano.

La sociedad civil se ha organizado para prestar ayuda a los inmigrantes, así se tienen los datos que existe una casa del migrante instalada en Tapachula, Chiapas, México, donde se hospedan cantidades que son elevadas de migrantes, les proporcionan techo por días mientras retoman el viaje a la Frontera Norte, hasta el año pasado se había prestado muy poco atención a la línea divisoria de los Estados de Chiapas, Tabasco, Campeche y Quintana Roo, México y los países vecinos de Guatemala, Belice y El Salvador, pero se ha dado una alza de migrantes de menores de edad para la frontera con los Estados Unidos, esto es un foco rojo que ha puesto más en alerta para atender más la frontera Sur de México, en la frontera entre Chiapas y Guatemala, los migrantes y los residentes locales frecuentemente cruzan el Río Suchiate en balsas o a pie, a menudo a plena vista de las autoridades mexicanas en el puerto oficial de entrada; la facilidad para el libre tránsito es porque las fronteras no se encuentran definidas, simplemente están marcadas por un poste o valla corta, el control que ha establecido el gobierno mexicano en la frontera sur, ha sido drástico al deportar a los migrantes sin darles la información necesaria para su tránsito, ni cuáles son sus derechos, tal es el descontrol que no tiene reportes oficiales de cantidad de personas deportadas.

La información sobre la situación de los inmigrantes en la Frontera Sur de México es escasa solo se obtiene por informes de las ONG y los medio de comunicación, como las publicaciones que hace los periódicos más reconocidos de Estados Unidos como son: The Washington Post, Los Angeles Times, quienes tiene como primera plana que es muy peligroso viajar por el territorio mexicano, lo que sufren los migrantes en la frontera Sur de México, esto ha preocupado al gobierno mexicano, en el año 2011 la Comisión Nacional de los Derechos Humanos de México señalo que 11,333 migrantes fueron secuestrados en un periodo de seis meses en el año 2006, esto fue aumentando, de ahí que mencionó que México es un país utilizado como tránsito para llegar a Estados Unidos, y tocó un tema importante como es la trata de personas, que durante el tránsito por el territorio mexicano, los inmigrantes sin distinción de sexo y edad han sido víctimas de tráfico sexual y trabajo forzoso, violando así sus derechos humanos.

La Comisión Interamericana de Derechos Humanos en su informe del año 2013, señaló que México a través de sus autoridades públicas ha sido tolerante en los secuestros de que han sido víctimas los inmigrantes centroamericanos en el tránsito por el territorio mexicano, menciona que recibieron más de 454 denuncias de violaciones de los derechos humanos, violaciones que en su mayoría han sido por los agentes del Instituto Nacional de Migración durante 2013, mencionó también que dichas violaciones a los Derechos Humanos cometidos en México quedan impune, los inmigrantes rara vez lo denuncian, que prefieren callar, en el año 2014 el Instituto Federal de acceso a la Información y Protección de Datos (IFAI), le ordenó al Instituto Nacional de Migración (INM) hiciera público los documentos que describen el plan del Programa Frontera Sur de México, lo cual fue negado, solo respondió que no tenía documentos que habían solicitado, el supuestamente más completo Programa 
Frontera Sur finalmente se anunció en julio de 2014, pero hasta la fecha no se ha publicado un documento con detalles sobre el plan.

La violación de los derechos humanos de los inmigrantes centroamericanos que transitan por la frontera sur de México, con destino a Estados Unidos, el Derecho Internacional nada ha podido hacer para erradicar las violaciones que han sufrido las personas durante su peregrinar, tanto que las propias personas se han armado de valor y se defienden de acuerdo a sus fuerzas físicas de los atracos que a veces los ha llevado hasta la muerte, cuando no logran salir vencedores de los atracos que sufren. Se estima que 200.000 migrantes indocumentados circulan cada año por México en búsqueda de su destino en el norte del país, es lamentable escuchar que México busca poner en marcha programas en defensa de los Derechos Humanos, pero en la práctica no mira las violaciones que comete el Instituto Nacional de Migración, en especial un caso reciente el día 8 de enero de 2015, en una zona llamada "La 72 " se encontraban más de 200 personas esperando el tren, por la mañana al llegar el tren salieron los inmigrantes que se encontraban en espera, pero en las vías estaban agentes del Instituto Nacional de Migración y Policía Federal de México, quienes se encontraban armados y encapuchados, quienes sin medir más se dedicaron a hacer cacería a los indocumentados amenazándolos, intimidándolos los corrieron utilizando diversas manera para asustarlos, diferentes medios de comunicación dieron la noticia de la que exhiben hasta fotografías y hay testigos de tal violación a los Derechos Humanos que sufren a diario los inmigrantes de la Frontera Sur de México.

La Constitución Federal mexicana, señala en el artículo $1^{\circ}$, que está prohibido la discriminación por origen étnico o nacional, el género, la edad, las discapacidades, condición social, condición de salud, religión, opiniones, preferencias sexuales, estado civil, o cualquier otra que atente contra la dignidad humana, que anule los derechos de las personas, es claro que si el Estado Mexicano ha firmado y se ha adherido a diferentes Tratados Internacionales, que protegen los derechos humanos y los que menciona en su propia Constitución y se aparta de lo consagrado en ellos, está violando los derechos humanos de las personas que se encuentran protegidas tanto por el Derecho Internacional, como por las Leyes Mexicanas, tan solo al no darles la protección y alimentos durante el tránsito por la Frontera Sur de México a los inmigrantes, de acuerdo a las diversas informaciones que emiten los medios de comunicación a nivel nacional e internacional los inmigrantes reciben tratos no dignos para ellos, además que han sufrido diversas violaciones a los Derechos Humanos y no han recibo el apoyo y protección que están plasmados en diversas normas jurídicas.

\section{CONCLUSIÓN}

La migración es un fenómeno que ha existido desde épocas antiguas y es tan frecuente que se ha proliferado en todo el mundo, que llega el momento que de tantas bajezas y humillaciones que sufren los inmigrantes que llegan a darle poco valor a su vida, el sufrir por problemas sociales y económicos, que pueden ser secuestrados por los grupos criminales y que en ocasiones hay complicidad con las mismas autoridades migratorias, es muy elevada las violaciones de los Derechos Humanos que persiste la impunidad en los abusos que sufren todas las personas que ha sido inmigrantes.

Las situaciones económicas que sufren en sus países de origen y falta de recursos económico obliga a los inmigrantes, que van de paso por la frontera sur de México hacia el país vecino del Norte los Estados Unidos, a caer en manos de grupos delictivos que con engaños los estafan y abusan hasta de su propia persona, en busca de mejor vida se enfrenta a 
diversos peligros que van desde ser atacados por animales salvajes hasta las violaciones de sus derechos humanos por las autoridades mexicanas, que en ocasiones también las autoridades migratorias son las responsables de cometer el delito, es decir que violan sus derechos humanos en vez de respetarlos y garantizar la protección de su derecho al libre tránsito, como lo disponen la Constitución Política de los Estados Unidos Mexicanos en los artículos $1^{\circ}, 2^{\circ}, 11$ y 33, así como los Tratados Internacionales en materia de Derechos Humanos.

Finalmente, existe la gran necesidad de darle seguimiento a la política migratoria en materia de Derechos Humanos y trato digno de las personas, pues la inmigración mundial no se ha agudizado por una simple moda, sino que es la evidencia real de las políticas gubernamentales, en las que no se consideran las necesidades reales del individuo, sino solamente el crecimiento de las grandes potencias económicas.

\section{BIBLIOGRAFÍA}

ACNUR. (10 de 05 de 1999). Declaración de Tlatelolco sobre acciones prácticas en el derecho de los refugiados en América Latina y el Caribe. En http://www.acnur.org/t3/fileadmin/scripts/doc.php?file= biblioteca/pdf/0010.

ACNUR. (16 de 11 de 2004). Declaración y plan de acción de México para fortalecer la protección internacional de refugiados en América Latina. En https://www.oas.org/dil/esp/Declaracion_y_Plan_ de_Accion_de_Mexico_2004.pdf.

AMERICANOS, O. D. (2012). Informe del Departamento de Estados Unidos de América. En http://ww w.migraciones.gov.ar/pdf_varios/estadisticas/G48952_WB_SICREMI_2012_SPANISH_REPORT_LR .pdf.

HUMANOS, C. I. (30 de 12 de 2013). Comisión Interamericana de Derechos Humanos. En Www.oas.org.

HUMANOS, C. I. (30 de 12 de 2013). Derechos Humanos de los migrantes y otras personas en el contexto de la movilidad humana en México. En http://www.oas.org/es/cidh/migrantes/docs/pdf/ Informe-Migrantes-Mexico-2013.pdf.

REPÚBLICA, G. D. (2014). Programas de Regularización Migratoria en México. En http://www.sin fronteras.org.mx/index.php/es/publicaciones/de-sin-fronteras/informes-anuales-2/376-los-programas-

de-regularizacion-migratoria-en-mexico-su-contribucion-a-favor-de-los-derechos-humanos-de-laspersonas-migrantes.

UNIDAS, A. C. (2001). Guía sobre el derecho internacional de los refugiados. En http://www.acnur. org/t3/fileadmin/Documentos/Publicaciones/2012/8951.pdf?view=1

UNIDAS, N. (10 de 12 de 1948). Declaración Universal de Derechos Humanos. En http://www.un.org/ es/documents/udhr/.

UNIÓN, C. D. (07 de 05 de 1981). Convención Americana sobre Derechos Humanos, adoptada en San Jose de Costa Rica. México: Diario Oficial de la Federación.

UNIÓN, C. D. (12 de 05 de 1981). Pacto Internacional de Derechos Económicos, Sociales y Culturales, Decreto Promulgatorio. México: Diario Oficial de la Federación.

UNIÓN, C. D. (22 de 06 de 1981). Pacto Internacional de Derechos Civiles y Politicos, Decreto Promulgatorio. México: Diario Oficial de la Federación.

UNIÓN, C. D. (01 de 09 de 1998). Protocolo Adicional a la Convención Americana sobre Derechos Humanos en materia de Derechos Económicos, Sociales y Culturales. "Protocolo de San Salvador", Decreto Promulgatorio. México: Diario Oficial de la Federación.

UNIÓN, C. D. (13 de 08 de 1999). Convención Internacional sobre la Protección de los derechos de los trabajadores migratorios y de sus familias, Decreto Promulgatorio. México, México: Diario Oficial de la Federación. 
UNIÓN, C. D. (25 de 07 de 2008). Reglamento de la Comisión Interamericana de Derechos Humanos, Decreto Promulgatorio. México: Periodico Oficial de la Federación.

UNIÓN, C. D. (27 de 01 de 2011). Ley sobre Refugiados, Protección Complementaria y Asilo Político. México: Diario Oficial de la Federación.

UNIÓN, C. D. (10 de 02 de 2014). Constitución Política de los Estados Unidos Mexicanos. México: Diario Oficial de la Federación.

UNIÓN, C. D. (19 de 05 de 2014). Ley de Nacionalidad. México: Diario Oficial de la Federación.

UNIÓN, C. D. (30 de 10 de 2014). Ley de Migración. México: Diario Oficial de la Federación.

\section{Breve currículo:}

\section{Rosa Cornelio Landero}

Licenciada en Administración, Licenciada en Derecho, Maestría en Administración Publica por la Universidad Juárez Autónoma de Tabasco, México; Doctoranda del programa de posgrado Doctorado en Métodos de Solución de Conflictos y Derechos Humanos, en la Universidad Juárez Autónoma de Tabasco, México. Profesora Investigadora de la Universidad Juárez Autónoma de Tabasco, México. 